\title{
Strategic foresight in the luxury industry: managerial perspectives
}

\author{
Benjamin Berghaus* \\ Competence Center for Luxury Management, \\ Institute of Marketing, \\ University of St. Gallen, \\ Switzerland \\ Email: benjamin.berghaus@unisg.ch \\ *Corresponding author
}

\section{Chiara Bossard and Laure-Line Baehni}

\author{
Institute of Marketing, \\ University of St. Gallen, \\ Switzerland \\ Email: chiara.bossard@student.unisg.ch \\ Email: laureline.baehni@gmail.com
}

\begin{abstract}
Luxury brands position themselves on creating offers created through unique savoir-faire. This positioning is commonly supported by substantial brand heritage. However, the ubiquity of heritage as a guiding compass to developing luxury brands leads to a new paradox: how does the notoriously heritage-conscious luxury industry deal with planning ahead? After all, today's luxury industry is not only an ever changing, ever more competitive environment - it is driven by consumer behaviour following the slightest changes in values and consumer culture. A lack of strategic foresight in such a volatile market might leave prestigious brands stranded missing critical turns of the market. In this study, we explored luxury executives' perceptions on strategic foresight. We identified five central factors that determine the degree of managerial engagement in strategic foresight. Moreover, we found three distinct perspectives based on different business sizes and ownership structures. Finally, we integrated our findings and outline a pragmatic research agenda.
\end{abstract}

Keywords: strategic foresight; luxury; luxury strategy; qualitative research; deliberate strategy; emergent strategy; luxury industry; luxury management; managerial perspective; managerial behaviour; strategy.

Reference to this paper should be made as follows: Berghaus, B., Bossard, C. and Baehni, L-L. (2015) 'Strategic foresight in the luxury industry: managerial perspectives', Luxury Research J., Vol. 1, No. 1, pp.76-90.

Biographical notes: Benjamin Berghaus joined the University of St. Gallen, Switzerland in 2010, first as the Manager of the Research Program for Luxury Brands, and since 2014, as the Manager of the Competence Center of Luxury Management. Previous to this, he worked as a Marketing Manager in the luxury market. His fields of interest are the particularities of the luxury market in all management disciplines as they are resulting from the marketing strategy of luxury positioning. 
Chiara Bossard is a student and Assistant Researcher at the University of St. Gallen. After graduating from Bocconi University in Milano in 2013, she started attending the Master course in Marketing, Services and Communication Management at the University of St. Gallen. In 2015, she joined the research team at the Institute of Marketing as a Student Research Assistant.

Laure-Line Baehni is a former student and researcher at the University of St. Gallen. She joined the Institute of Marketing in 2013 and collaborated as a Research Assistant to the Research Program for Luxury Brand Development. She is now working for a globally leading online shop for luxury products.

\title{
1 Introduction
}

\begin{abstract}
Martin Wiesmann's dream began in 1985, when returning from the Motor Show in Essen, he saw an Autobianchi on the highway and thought: "I can do this, too!". Eight years later, in 1993, the first Wiesmann was born. Martin brought the ideas and his brother Friedhelm the capital. In this manner, the Wiesmann brothers built a luxury company in classic German entrepreneurial style, by concentrating on creating truly unique cars. By 2008, the dream became a nightmare; suddenly everything in the market changed. The company's crisis was caused mainly by the founders' inability to foresee and plan for market changes, as well as to adapt to the future. The company's inability to adapt to the new market situation led to its insolvency in 2013 and, finally, its bankruptcy in 2014, when Wiesmann had to close up shop.
\end{abstract}

Adapted from Freitag (2014)

Positioning a successful luxury offering depends to a large part on brand and organisational heritage [Kapferer and Bastien, (2009), p.93]. In creating high-end products, heritage leads to an accrual of specific know-how over time, which eventually engrains itself into these businesses (Dion and Borraz, 2015). However, this heritage not only provides the gradual accumulation of skills and experience. Brand heritage also acts a reassurance to the customer, as a basis for trust in a specific manufacturing focus (Wiedmann et al., 2011). While the high price of a luxury good may be a conventional (if rather superficial) indicator of quality, knowledge and awareness of the long tradition and specialisation of a brand is a prerequisite to stimulating consumers' trust in purchasing something extraordinary at an extraordinary price (Hur et al., 2014). A rich history of famous customers and creators, the aura of a royal court containing the product, or lively anecdotes in the context of one or another product, all play their part in sweetening the offer.

However, the role of the organisational 'pedigree' and consequential attention to the rear-view mirror leaves an important question unanswered: how do organisations in the luxury industry deal with looking into the future? Do they do it at all? The delayed recognition of the digital channels for catering to customers [Kapferer and Bastien, (2009), p.83; Okonkwo, 2009], the commonly very traditional company structures (Riguelle and van Caillie, 2014), as well as a stubborn aversion to substantial functional advances in many product categories such as watch-making, jewellery, and fashion, lead us to question whether organisations in the luxury industry plan for the future at all and, if so, how they do it. 
The future is uncertain - be it the market's future (Naik et al., 2005), the economy's (Arthur, 1999), or even the own organisation's. Prediction remains a difficult managerial challenge. Strategic foresight and the associated measures, implemented either implicitly or explicitly, can help to prepare effectively for changes. Strategic foresight integrates the beliefs, procedures, and tools of trend research and conceptualisation of the future to support strategic decision making in organisational settings. Foresight is ideally understood as a 'projection of the future', including how these projections are made. The concept is frequently used to describe all systematic and decision-oriented activities with a broader time horizon. Strategic foresight aims to support strategic decision making and the initiation of planning and innovation-oriented activities. Strategic foresight has three central tasks in the business setting: to prepare strategic decisions, ensure the long-term competitiveness of the business, and sustainably strengthen the learningand innovation-capabilities of the company [Müller, (2008), p.20]. From a managerial perspective, the notion of strategic foresight has become more relevant in the past decade, due to the increasing number of business-threatening risks induced by the rising complexity of international sales networks and ever more intricate brand structures, parallel to a rising number of local and global crises. Thus, today, the advantages are becoming progressively more evident of dedicating more time to strategic foresight in the c-suite, in order to ensure that executives are not developing managerial blind spots that risk business performance or even survival [Metayer, (2012), p.67].

In the context of the luxury industry, strategic foresight assumes an even more pressing relevance. Luxury consumption may be driven by several relatively stable consumer behaviour phenomena (Johnson and Vigneron, 1999), but is even more fundamentally dependent on an inherently dynamic array of values idealised by the respective consumer culture (Nwankwo et al., 2014; Loureiro and de Araujo, 2014). These cultural values presently appear to be changing faster than ever, giving rise to new phenomena like inconspicuous luxury (Schimpfossl, 2014), non-commercial and sustainable luxury (Gibson and Seibold, 2014; Sexton and Sexton, 2014; Ahn and Pearce, 2013), artisan-collaborative luxury (Hicks and Hicks, 2014; Kapferer, 2014) and digital luxury (Okonkwo, 2010). In most cases, luxury brands have been 'late to the party', which leads us to the central question: is the notorious aversion to advancement necessary to a luxury business strategy, or does a strategic-foresight practice in fact exists for luxury?

The aim of this paper is to consider how managers in the field of luxury perceive the challenge of strategic foresight. Moreover, we explore whether some systematic differences in the approach to strategic foresight are tied to sector and/or size, and other variables characterising a company. Finally, we aggregate the most commonly used methods in strategy foresight for luxury brands.

This study presents three central findings. First, it identifies the main aspects which determine how strategic foresight is integrated into the organisation, namely:

1 self-reliance

2 agility

3 proximity in customer relationship

4 innovation

5 competitive environment. 
Second, the analysis reveals three distinct and different perspectives on the topic of strategic foresight in the luxury segment. These perspectives are related to the individual development stages and ownership structures of the respective firms:

1 the entrepreneurial perspective

2 the small- and medium-enterprise (SME) perspective

3 the business unit or corporate subsidiary perspective.

Finally, we found further evidence of a dominant focus on resources instead of markets among (particularly smaller) luxury companies. We close with a discussion on whether installing a strategic foresight infrastructure makes sense for all organisations, or whether some businesses in the luxury market have found a way to be safely less attentive to 'weak signals' that are conventionally valuable to market orientation firms.

\section{Methodology}

This study aims at generating a comprehensive account of a complex managerial challenge and the solution by gathering and synthesising a diverse selection of managerial perspectives. To account for the complexity involved, we employed a qualitative research design and based our research on semi-structured interviews. The interviews were carried out in early 2014 with participants of a European luxury-goods manager panel comprising of $37 \mathrm{CEOs}$ in eight sectors of the luxury market.

\subsection{Data collection}

Data was collected through phone interviews and equivalent written questionnaires if participants could only answer asynchronously. There were a total of 15 participants of whom six responded by way of phone interviews and nine by completing the qualitative questionnaire. Both phone respondents and written respondents were asked the same questions. In the phone interviews, interviewees were encouraged to elaborate further on their opinions. Interviewees represent companies associated with the European Cultural and Creative Industry Alliance, but also other specialised luxury companies. The questionnaire was designed around the broad core question "How to plan beyond the next bend?".

\subsection{Sample}

The sample consists of 15 executives of European luxury companies (six from Switzerland, five from Germany, two from England, one each from France and Italy), all but two are CEOs and in one third of the cases, both CEO and founders of the company. We specifically invited top executives, since they are directly involved in developing the strategy and business model of the companies and were likely to provide the most significant knowledge on strategically planning the organisational future as a whole. Interviews were conducted in both English and German, according to the requests of the particular interviewee. In developing the sample, we chose to include representatives from various industries involved in the luxury business. Furthermore, we aimed at sample variance in terms of organisational size, origin, and ownership structures, in order to 
obtain a varied account of the industry as a whole. Among the 15 participants, eight industries were represented: watches (five), hospitality (three), jewellery (two), retail, home and interior design, food and beverage, fashion, and cosmetics (one each). Companies were also divided into three groups based on size: 200 employees and more (seven), less than 200 employees but more than 50 (six), less than 50 employees (two).

\subsection{Data analysis}

Data was collected and coded following the grounded theory approach (i.e. axial, open, and selective coding) using Atlas.ti. For reasons of consistency, codes in English were also used to code the data originally gathered in German. Different criteria were chosen to attribute a code to a statement, but each segment coded introduced new insights or underscored existing insights with regard to the central research question of how the investigated luxury brands deal with strategic foresight.

\section{Findings}

\subsection{Five facets of strategic foresight in luxury}

The first main finding of this study is the identification of five distinctive aspects that determine the role of strategic foresight in an organisation. The panellists pointed to five main factors which influence the degree of implementation of strategic foresight measures within their organisation:

1 self-reliance

2 proximity between customer and organisation

3 role of business agility

4 innovative drive of the company

5 competitive environment and strategic aim.

Below, we briefly present the individual facets and illustrate their meaning by presenting the most compelling panellist statements.

\subsubsection{Self-reliance}

Among the most prominent factors, we found luxury-specific self-reliance to play an important role. By self-reliance of a business or a manager, we mean the degree to which the executive sees business opportunities arising from within the company, as opposed to from the market outside. This understanding of managerial self-reliance is closely related to the prominent resource-based view (Barney, 1991, 2001; Barney et al., 2011). We found self-reliance to be a factor limiting strategic foresight in luxury-goods organisations. Just as Kapferer and Bastien $(2009$, p.65), for example, posit in their 24 anti-laws of luxury, most of the panellists pointed to the need to develop the organisation from its internal capabilities and resources, rather than placing the emphasis on identifying and leveraging external potential, or even seeking external help in doing so. 
There are multiple reasons for luxury businesses to stick to their trades. Most prominently, a brand positioning built upon the excellence of manufacturing a specific category of offers generally negates the inclination to also create offers in different categories, but with the same level of quality. As a manager from watch-making explained:

I think that the old guideline "stick to your skills" fits very well with our traditional company. Furthermore, we are quite busy manufacturing and selling watches - we have neither the time, nor are we inclined to do anything other than this on the same level. (...) I, personally, ask myself where some luxury brands get the confidence to believe that they will succeed in categories where other companies have taken a hundred years to drive their products to perfection.

Closely connected to the idea of the company concept inhibiting the need for strategic foresight, there is the role of the central creative figure, which in many luxury brands sets the guidelines for future creations. The founder of a small, highly specialised and high-end watch-making business explained:

My company is extremely unique in many ways, but in one way which is clear, it's extremely self-centered and creatively driven. I don't give a damn about what the market wants. We don't give a damn, what the fashion, the trend, the market wants. We create what we believe in and then we have to find ways to get people to understand what we are doing [...].

While in the above quotation, self-reliance appears as an inhibitor to engagement in luxury strategic foresight, the perspective of an entrepreneurial luxury brand appears to be different. Among start-ups, strategic foresight is commonly ingrained in the organisational fabric itself; a market niche has been identified and the entrepreneur's endeavour is directed at investing resources to capitalise on this particular insight in the future. For example, as the managing director and founder of a jewellery company explained:

We built the company because we believe that something needs to be different. We need to have a different approach to the problem, or the customers need to have a different need for buying high-value jewelry in the future. Therefore, I would say the company was founded on the basis of strategic foresight.

Overall, we can report that a general self-reassurance and reliance on one's own resources and know-how to produce extraordinary services and products is a key inhibiting factor to strategic foresight and market orientation. We found numerous comparable sentiments made by other panellists, indicating that external input may be, at least to a degree, incompatible with the management of luxury brands. Only when the leading mission of a business in the luxury market is aimed at leveraging novel potential in the market, does self-reliance become a promoter of strategic foresight in the luxury industry. In more metaphorical terms, luxury executives rely more on knowing what their 'ship and crew' can achieve during their business journey, than investing substantial resources to learn about today's "weather forecast for every leg of the trip" - information that will likely be outdated anyhow when it becomes effective. Rather, they rely on finding the best route every day. 


\subsubsection{Proximity in customer relationship}

The second most pervasive factor impacting on the evaluation of strategic foresight measures appeared to us as rooted in the proximity of the stakeholder relationship between business and customer. In this respect, greater proximity between the organisation and the customer means departing from a broader and rather statistically informed market-orientation relying on a quantitative analysis of 'big data', to derive synthesised insight from myriads of everyday customer interactions. Instead, greater proximity means approaching an individual customer-orientation by forging and maintaining personal relationships between key representatives of the firm and individual customers. As we see more opportunities for luxury businesses to engage in such customer-oriented interactions downstream, we both expected and found only a few panellists who stated that they would describe their business as lacking individual, personal connections to their customer base. That is, luxury appears as a business model that invites closer relationships between brands and their clientele. One panellist, the $\mathrm{CEO}$ of an organisation in the furnishing and interior-design sector, put it most aptly:

[Our business is about creating warm, personal contact] and the organization and its employees must reflect that. Our employees already have a high level of education. But we want to go beyond that and also increase the influence of cultural elements. We invite our people to museums, they get involved with [city of business residence], and they talk about that. Our people have a certain style in their appearance. All of this is about enabling a positive, personal relationship with our customers and to make a solid case for why they will feel comfortable working with us, that we understand them and that we will take good care of them. Confidentiality plays a role, decency and appearance play a role - really everything that is fundamental to personal relations between people. Not sending out brochures, websites or anything else. No - if you come here, we will show you how we work. We will introduce you to the craftsman, let her or him speak, so that you get the idea "He works for me and he is a good guy, and this guy built my cabinet". [...] These are our resources, these interpersonal relations which, in the end, lead to a customer saying "I want these people to take care of my home".

We found that luxury, as a business model, drives close customer-brand relationships, which in turn, limit the risk of the brand missing out on a crucial change in demand. Thus, we predicted and indeed found the impact of customer relationship proximity on strategic foresight measures to be negative: those organisations that we identified as maintaining closer, more personal relationships with their customers were less eager to develop (additional) strategic foresight capabilities. An executive of a company active in the hospitality sector explained:
Luxury companies generally align their products so as to be very customer- oriented. They develop them with a specific individual or a small group of customers in mind. Therefore, they don't face the problems of mass providers, and to a certain extent premium providers, which become too big, lose contact and no longer learn from their customers.

Overall, we saw the degree of proximity between the organisation and their customers to be elevated in our panel. This led us to make a distinction between the terms market-orientation and customer-orientation - two concepts all too readily and commonly equated. Luxury tends to inspire and support more customer-oriented business models, which in turn leads to a closer integration of the customer into shaping the offers. This closer integration counteracts a more substantial need for strategic foresight, by 
acting as if allowing an expert pilot to support the navigation of the business when approaching the metaphorical safe harbour of a successful offer.

\title{
3.1.3 Agility
}

Because strategic foresight aims at long-term prediction of the business environment of an organisation, that will take a long time to change course, its natural alternative is increasing the manoeuvrability of the business itself. Business agility is the ability of a company to rapidly respond to change by adapting its initially stable configuration (Wieland and Wallenburg, 2012). Particularly for small and start-up luxury companies, business agility is a disincentive toward excessive planning. If the business is agile so that its course can be adjusted quickly, there is little to gain from extensive planning and long-term strategising. While the benefits diminish, the cost of the foresight measures remains as high as the uncertainties involved in any outcome of the strategic foresight process. Two of our panellists, a founder of a jewellery company and founder of a watch-making company, described the interrelation between agility and strategising, as well as its interrelation with self-reliance:

We have to adapt flexibly. However, we have no one in the company, other than us founders, who actively lives this and looks ahead. But if we notice a trend, then we also adapt quickly. It is not as though we have to control a supertanker.

\begin{abstract}
Strategic foresight is not necessary in our niche. We develop new ideas independently of others. Sometimes, our competitors follow us a few years later with similar products. We go quite unusual ways - that makes long-term planning rather difficult. A rough outline of a plan is made, but that can change easily.
\end{abstract}

While the notion of business agility is traditionally linked to organisational size, it is not exclusive to entrepreneurial businesses. Agility is also crucial to many businesses medium-size businesses, as this executive from the hospitality sector explained:

We must try to be flexible by all means, to adapt our rigid units (a single room, a double room, or a suite) to new trends, markets or business fields. I must be able to react without having to constantly rebuild.

Business agility thus appears as the central counteracting factor to strategic foresight processes. Here, we found the strongest connection between one of our identified factors and strategic foresight implementation, as the resulting organisational behaviour under scrutiny. To maintain the previously introduced metaphorical setting, the relationship between agility and the need to generate strategic foresight resembles the manoeuvrability of the ship steered by its executive captain. Those who steer a large ship need more foresight to adjust the course; those who command a smaller vessel can act much more efficiently without large-scale planning. Captains of large and powerful brands, who manage to change course nimbly and precisely, will win the race.

\subsubsection{Innovation}

Foresight not only provides nice-to-know advance information on market conditions, it is commonly the basis for substantial, long-term investments in product portfolio innovation, manufacturing sites, and personnel capabilities. As one panellist put it: 
Internally, we have a 10-year plan. We need it too - in capacity and investment. I would not have a good conscience training 20 new young people in clockmaking if I didn't have a clear plan that they will still be needed in 10 years. They want to stay watch-makers for the next 40 years.

Thus, in contrast to the somewhat detrimental effects of self-reliance, close customer relationships, and business agility, innovation appears to drive strategic foresight needs. A panellist steering a watch-making company stated:

We used to bring out a really new innovation every two or three years: a new clockwork, a new product family etc. Today, we have at least three new clockworks each year and every seven to ten years, more substantial technological innovations. That is something we have anchored strategically, backed with resources. We aim to "catch these waves" and have solutions that do not mean cutting production, but rather bringing about innovation by utilizing resources, with the understanding that the market is always keen.

Even beyond the traditional outside-in focus of luxury brands, innovation fosters strategic foresight. Among the panellists who also founded their organisations, one jeweller pointed out the role of strategic foresight capabilities in order not to miss any central trends potentially relevant to their industry:

Think about what has happened in the field of mobile telephones in the past 10 years. How they look and how they act as a real companion today. In five years, they will evolve to track everything, from our entire bodily functions, simultaneously acting as a defibrillator, all together, medical monitoring equipment and so on and so forth. 3D-printers are still in their infancy today and are thus achieving mediocre results - but in 2025 [3D-printers might play an important role, even in luxury jewelry].

Likewise, in the context of generating distinctive customer experiences, managers of leading companies take into account technological trends they find in the vicinity of their sector and consider innovation potential for their own business. This requires constant transferring, forecasting, evaluating, and reconsidering of a multitude of technologies.

Overall, we found that constant need for and indeed internal drive of luxury brands toward innovation supports the need for at least some degree of planning and foresight, as considerable investments are involved. While luxury managers appear to have developed a somewhat uneasy relationship with strategic foresight, the risk of sinking investment into the development of offers, facilities, and personnel that will not succeed in the market is among the strongest reasons to plan ahead. In nautical terms, it is those captains who gear up to journey into unchartered waters who invest the most time in at least rudimentary planning.

\subsubsection{Competitive environment and strategic objectives}

The need for strategic foresight is furthermore supported by challenging competitive environments. While individual organisations by themselves might operate well in daily business without extensive planning, growing storms in the global (industrial) or local (segmental) competitive environment can create an advantage for those who can read the storm's signs and prepare a strategy well in advance. The founder of a small Swiss watch-making business explained:

So this is why we decided already two years ago that when we hit the turnover threshold. That we defined, which happened last year, we would not grow 


\begin{abstract}
anymore. We can do this, because we are a private shareholder company, and there is nobody waiting for dividends or profits or things like that. So we have decided from now on not to grow this company anymore. We are going to perpetuate it, continue what we are doing at our turnover ceiling, be supercreative, re-innovate, reinvent ourselves, but we are not going to grow for two reasons: a) we don't want to grow to a size where we start needing to compete with the big players, b) we don't want to have any middle management in our company $[. .$.$] . So from there onwards, we want to stay exactly where we are$ and continue being the disruptive brand we are.
\end{abstract}

In this context, we find a particularly interesting combination of both static and dynamic elements of our panellists' business strategies: key characteristics such as size, turnover and availability appear to be so inherently interwoven with the organisational identity, that they may reasonably be assumed as fixed. These static and identity-supporting characteristics, however, do not necessarily lead to an organisation entirely frozen in time. Instead, the strategic decision on size supports agility, innovation and disruptiveness, while at the same time limiting competitive pressure.

To sum up this section on the five central factors fostering or hampering engagement in strategic foresight, we report three strategic-foresight-inhibiting factors:

1 organisational self-reliance

2 customer relationship proximity

3 business agility as the preferable alternative.

On the other hand, we found two factors that supported the engagement in and overall attitude of luxury executives toward strategic foresight.

\title{
3.2 Three perspectives on strategic foresight in luxury
}

Adding to the level of factors impacting on organisational behaviour in terms of the described strategic foresight, we found three distinct and different perspectives of the topic of strategic foresight in the Luxury Executive Panel and attributed them to the individual development stages/ownership structures of the respective firms. The three strategic foresight perspectives are:

1 luxury start-up perspective

2 luxury SME perspective

3 luxury business unit/corporate subsidiary perspective.

\subsubsection{The luxury start-up perspective}

The entrepreneurial perspective of strategic foresight in luxury implies that the respective luxury-positioned company has been established during the past two decades. Agility and dynamism is part of the daily business. Also, the business proposal itself is commonly strongly associated with strategic market foresight from the founders - be it the investment in a new product category or the emphasis on a particular new sales channel. With this perspective, the central creative person, most likely the founder, the company concept, and information derived from the close relationship with consumers drive the strategic orientation of the company. There is a certain foresight regarding internal 
aspects of the company, but not on the long-term development of the market, beyond what the company itself set out to accomplish.

We might look five years into the future, maximum. With us, everything else is so dynamic and changes all the time, in principle on a weekly basis.

So, the closest that our company comes to strategic foresight is really looking at how the customer behaves, where the customer comes from and then to do things your own and go from there.

In our company, all the strategies and long-term planning are determined by me as the CEO, based on my instinct and advice from my most important people.

\subsubsection{The luxury SME perspective}

The amalgamated perspective from the luxury SME is that some methods of strategic foresight are implemented, but there is generally no substantial procedural framework or large administrative overhead of any kind. The SME perspective shows that these businesses build on agility and flexibility. Given the probably greater complexity of businesses, perhaps through having expanded into an international sales network etc., managers of SMEs tend to see greater variability and short-term changes in international business as a threat to the investment made in substantial planning. At the same time, there is a strong market-oriented sense of competition that fuels the general need for business growth, for which future opportunities must be evaluated and targeted, in turn creating value from more institutionalised strategic foresight.

Strategic foresight is most likely a mix-and-match of methods for us.

If you only think about resources and your own strengths and ignore market forecasts, then it is actually the most resilient basis to think that planning can work quite well.

Flexibility is the key to solving hypotheses about the future. These hypotheses will most likely no longer be correct anyway when the time comes.

Especially in a situation where the outside world already rotates three times a day, it is probably better to concentrate on resources and utilize them in the best possible way.

We do not plan in detail beyond a two-year horizon.

\subsubsection{The luxury business unit/corporate subsidiary perspective}

With this perspective, we see general structures of planning and forecasting as imposed by the corporate owners. Procedures and methods appear more standardised and implemented as regular approaches to extending and re-aligning prior planning. At the same time, there is an inherent mistrust in the value of strategic foresight measures directed at predicting market behaviour that goes beyond a three to five year planning horizon. While larger change processes are understood as taking considerable amounts of time, planning these processes can be part of long-term planning. These initiatives are usually developments inside and not outside the organisation.

There is a clear planning structure. We use a three year strategy compass, and one year budget planning, consumer insights and trend monitoring. 


\begin{abstract}
Assumptions are made according to the PESTEL principle (political, economic, social and technological, environmental and legal analysis). Based on these assumptions, a balanced scorecard is developed.
\end{abstract}

There is a five-year strategic plan. Also, products and their innovation need to be planned five years in advance.

Taking these individual perspectives into account, we arrive at a rough, integrated understanding of the extension of implemented strategic foresight methods, through the common organisational development cycle from a small luxury company managed by its entrepreneur, via the luxury SME to the luxury brand, operated as a business unit or corporate subsidiary. Consistent with our expectations, the focus of strategic foresight increases with decreasing agility and flexibility - because entrepreneurs in small companies can integrate customer feedback relatively directly and immediately. Managers of SMEs rely on some degree of foresight to justify larger investments, but do so reluctantly, as they regard the market as changing too quickly for substantial market-oriented foresight to be of much value. Executives of larger and corporate-owned companies are likely to be somewhat restrained by corporate directives or strategic plans tuned to the corporate strategy, and thus build more on strategic foresight processes and methods.

\title{
4 Discussion
}

\subsection{Theoretical implications}

From a theoretical point of view, this study sheds new light on the research dealing with emergent and deliberate strategy (Mintzberg and Waters, 1985), with a focus on the luxury field. By systematically analysing managerial perspectives stated by executives in the luxury market, we have added to our understanding of how strategic foresight is implemented in luxury companies. We found that the understanding of business strategy by entrepreneurs and SMEs appear to be as more of an emergent strategy development than a deliberate one. This means that managers prefer to rely on their ability to adapt to the changing business environment and consider strategy rather as an outcome of business operations than from meticulously designing their course of action in advance. On the other hand, brands that are part of larger corporations are keener on carefully planning their future based on external and internal variables. Among other reasons, this is likely to be the case, as the luxury subsidiary or unit appears as an investment to the operating cooperation - an investment that is expected to provide a certain, reliably generated financial performance.

\subsection{Managerial implications}

Throughout our study, we arrived at the conclusion that strategic foresight is perceived differently by top-level executives in the luxury business. In many cases, it is criticised as too expensive, often not work as planned, and many managers find it more useful simply to adjust to changes in the market as they occur. We identified five factors which influence the way executives approach strategic foresight, and each factor can have a positive or negative effect on the way strategic foresight is perceived. The first factor deals with the role of self-reliance of luxury businesses. Luxury companies generally 
derive a substantial amount of their identity from being resource-oriented. The second factor is agility, with smaller more agile companies rather relying on their ability to adapt quickly to new market situations and therefore view strategic foresight as an unnecessary investment. The third factor, a close customer relationship, also has a negative impact on the drive businesses develop toward implementing strategic foresight. Companies which base their business model on a close relationship with the customer feel less of a need for strategic foresight, as they can rely on first-hand information from more integrated customers. On the other hand, companies which are strong in innovating, and businesses that operate in highly competitive industry sectors, see strategic foresight as a necessary tool for survival.

\subsection{Limitations}

Our research design provided a first glimpse into the complex reasoning for and against strategic foresight engagements in the luxury market. Given our immediate, but also pragmatic sampling, using a pre-existing convenience sample in our panel, our study was not insulated against sampling bias. Thus, our findings constitute a collection of impressions and their synthesis. The study sample is based largely on companies from the ECCIA organisation. However, the international organisation does not include all companies associated with luxury in Europe, while other companies have also joined the sample. Overall, the study's limitations impact on the generalisability of the findings. We hope, however, that these initial findings will inspire additional research in this field.

\section{Conclusions}

Although there are different approaches to strategic foresight, the capability to systematically arrive at plausible future scenarios and to develop a planned course of action appears beneficial in the luxury business. Firstly, as the business model of a luxury business is driven by societal values that manifest themselves in the respective consumer culture, a change in societal values without its recognition by those companies who provide luxury goods, can add substantial risk to their business. Secondly, the notoriously heritage-oriented luxury strategy requires businesses to constantly rejuvenate their brands, not only to avoid seeming stagnant, but also to keep up with societal changes in the market. This requires cognitive and procedural capabilities in planning and implementing, as well as frequent reviewing of the company's future vision. As a third reason to consider an efficient approach to strategic foresight for a business, the challenge of sustainable growth for luxury brands enters into the discussion. In many cases, luxury brands grow rather quickly, which can undermine their exclusive value proposition. The combination of a strategic aim with regard to brand growth, as well as the definition of some key variables (e.g., predictions of sector growth, the most challenging competitors, potential new entrants to the market) together with surveillance through rudimentary strategic foresight measures, may help to sustain a healthy growth corridor for the luxury business.

Taking into account the potential that strategic foresight might hold for luxury businesses, we suggest strategic planning for a narrower timeframe, and strategic foresight for a broader timeframe in advance, as future research fields of great opportunity. Our own aim is to explore the topic further and to develop a pragmatic 
framework that may be employed as a set of checklists, taking into account the identified factors, but also the different perspectives along the business lifecycle. We aim to develop this framework into an efficient and immediate tool, facilitating a frequent revision of strategy and helping managers to understand more clearly the environment of their own company.

\section{References}

Ahn, Y. and Pearce, A. (2013) 'Green luxury: a case study of two green hotels', Journal of Green Building, Vol. 8, No. 1, pp.90-119.

Arthur, W.B. (1999) 'Complexity and the economy', Science, Vol. 284, No. 5411, pp.107-109.

Barney, J. (1991) 'Special theory forum: the resource-based model of the firm: origins, implications, and prospects', Journal of Management, Vol. 17, No. 1, pp.97-98.

Barney, J. (2001) 'Resource-based theories of competitive advantage: a ten-year retrospective on the resource-based view', Journal of Management, Vol. 27, No. 6, pp.643-650.

Barney, J., Ketchen, D.J. and Wright, M. (2011) 'The future of the resource-based theory', Journal of Management, Vol. 37, No. 5, pp.1299-1315.

Dion, D. and Borraz, S. (2015) 'Managing heritage brands: a study of the sacralization of heritage stores in the luxury industry', Journal of Retailing \& Consumer Services, Vol. 22, No. 7, pp.77-84.

Freitag, M. (2014) 'Cursed dream car - how Wiesmann drove into bankruptcy', Manager Magazine [online] http://www.manager-magazin.de/lifestyle/artikel/a-994663.html (accessed 31 March 2015).

Gibson, P. and Seibold, S. (2014) 'Understanding and influencing eco-luxury consumers', International Journal of Social Economics, Vol. 41, No. 9, pp.780-800.

Hicks, D.L. and Hicks, J.H. (2014) Jealous of the Joneses: Conspicuous Consumption, Inequality, and Crime, Vol. 66, No. 4, pp.1090-1120.

Hur, W., Kim, M. and Kim, H. (2014) 'The role of brand trust in male customers' relationship to luxury brands', Psychological Reports, Vol. 114, No. 2, pp.609-624.

Johnson, L.W. and Vigneron, F. (1999) 'A review and a conceptual framework of prestige-seeking consumer behavior', Academy of Marketing Science, Vol. 1, No. 1, pp.1-15.

Kapferer, J. (2014) 'The artification of luxury: from artisans to artists', Business Horizons, Vol. 57, No. 3, pp.371-380.

Kapferer, J. and Bastien, V. (2009) The Luxury Strategy. Break the Rules of Marketing to Build Luxury Brands, Kogan Page, London.

Loureiro, S.M.C. and de Araujo, C.M.B. (2014) 'Luxury values and experience as drivers for consumers to recommend and pay more', Journal of Retailing and Consumer Services, Vol. 21, No. 3, pp.394-400.

Metayer, E. (2012) 'Pay attention to the "blind spots"', Internal Auditor, Vol. 69, No. 3, pp.67-69.

Mintzberg, H. and Waters, J.A. (1985) 'Of strategies, deliberate and emergent', Strategic Management Journal, Vol. 6, No. 3, pp.257-272.

Müller, A.W. (2008) Strategic Foresight. Prozesse strategischer Trend- und Zukunftsforschung in Unternehmen, Dissertation at University of St. Gallen.

Naik, P.A., Raman, K. and Winer, R.S. (2005) 'Planning marketing-mix strategies in the presence of interaction effects', Marketing Science, Vol. 24, No. 1, pp.25-34.

Nwankwo, S., Hamelin, N. and Khaled, M. (2014) 'Consumer values, motivation and purchase intention for luxury goods', Journal of Retailing and Consumer Services, Vol. 21, No. 5, pp.735-744. 
Okonkwo, U. (2009) 'Sustaining the luxury brand on the internet', Journal of Brand Management, Vol. 16, Nos. 5/6, pp.302-310.

Okonkwo, U. (2010) Luxury Online: Styles, Systems, Strategies, Palgrave Macmillan, Basingstoke.

Riguelle, F. and van Caillie, D. (2014) 'Competing as a luxury SME', in Berghaus, B., Reinecke, S. and Müller-Stewens, G. (Eds.): The Management of Luxury: A Practitioner's Handbook, pp.275-286, Kogan Page, London.

Schimpfossl, E. (2014) 'Russia's social upper class: from ostentation to culturedness', British Journal of Sociology, Vol. 65, No. 1, pp.63-81.

Sexton, S.E. and Sexton, A.L. (2014) 'Conspicuous conservation: the Prius halo and willingness to pay for environmental bona fides', Journal of Environmental Economics \& Management, Vol. 67, No. 3, pp.303-317.

Wiedmann, K., Hennigs, N., Schmidt, S. and Wuestefeld, T. (2011) 'Drivers and outcomes of brand heritage: consumers' perception of heritage brands in the automotive industry', Journal of Marketing Theory \& Practice, Vol. 19, No. 2, pp.205-220.

Wieland, A. and Wallenburg, C.M. (2012) 'Dealing with supply chain risks: linking risk management practices and strategies to performance', International Journal of Physical Distribution \& Logistics Management, Vol. 42, No. 10, pp.887-905. 